\section{(6) OPEN ACCESS}

\title{
Visual acuity, self-reported vision and falls in the EPIC-Norfolk Eye study
}

\author{
Jennifer L Y Yip, ${ }^{1,2}$ Anthony P Khawaja, ${ }^{1,2}$ David Broadway, ${ }^{3}$ Robert Luben, ${ }^{1}$ \\ Shabina Hayat, ${ }^{1}$ Nichola Dalzell, ${ }^{1}$ Amit Bhaniani, ${ }^{1}$ Nicholas Wareham, ${ }^{4}$ \\ Kay-Tee Khaw, ${ }^{1}$ Paul J Foster ${ }^{2}$
}

\begin{abstract}
${ }^{1}$ Department of Public Health \& Primary Care, University of Cambridge, Cambridge, UK ${ }^{2}$ NIHR Biomedical Research Centre for Ophthalmology, Moorfields Eye Hospital and UCL Institute of

Ophthalmology, London, UK ${ }^{3}$ Department of

Ophthalmology, Norfolk and Norwich University Hospital,

Norwich, Norfolk, UK

${ }^{4}$ MRC Epidemiology Unit,

University of Cambridge School of Clinical Medicine,

Cambridge, UK
\end{abstract}

\section{Correspondence to} Dr Jennifer L Y Yip, Department of Public Health and Primary Care, Institute of Public Health, Forvie Site, Robinson Way, University of Cambridge, Cambridge CB1 8RN, UK;

jlyy2@medschl.cam.ac.uk

Received 13 August 2013 Revised 29 October 2013 Accepted 17 November 2013 Published Online First 12 December 2013

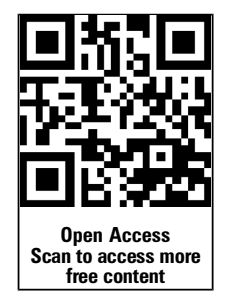

\begin{tabular}{l}
\hline To cite: Yip JLY, \\
Khawaja AP, Broadway D, \\
et al. Br J Ophthalmol \\
2014;98:377-382.
\end{tabular}

\begin{abstract}
Purpose To examine the relationship between visual acuity (VA) and self-reported vision (SRV) in relation to falls in 8317 participants of the European Prospective Investigation into Cancer-Norfolk Eye study.

Methods All participants completed a health questionnaire that included a question regarding SRV and questions regarding the number of falls in the past year. Distance VA was measured using a logMAR chart for each eye. Poor SRV was defined as those reporting fair or poor distance vision. The relationship between VA and SRV and self-rated falls was analysed by logistic regression, adjusting for age, sex, physical activity, body mass index, chronic disease, medication use and grip strength.
\end{abstract}

Results of 8317 participants, 26.7\% (95\% Cl 25.7\% to $27.7 \%$ ) had fallen in the past 12 months. Worse VA and poorer SRV were associated with one or more falls in multivariable analysis (OR for falls $=1.31,95 \% \mathrm{Cl}$ 1.04 to 1.66 and $O R=1.32,95 \% \mathrm{Cl} 1.09$ to 1.61 , respectively). Poorer SRV was significantly associated with falls even after adjusting for VA $(O R=1.28,95 \% \mathrm{Cl}$ 1.05 to 1.57).

Conclusions SRV was associated with falls independently of VA and could be used as a simple proxy measure for other aspects of visual function to detect people requiring vision-related falls interventions.

\section{INTRODUCTION}

Falls are an important cause of morbidity and mortality in older people, with more than a third of community dwelling adults aged 65 years and older experiencing a fall each year. ${ }^{1-3}$ Serious injury such as fractures and traumatic brain injury occur in approximately $10 \%$ of falls. ${ }^{4}$ In the UK, falls are estimated to account for between $10 \%$ and $25 \%$ of all local health and social care spending on older people, with a projected rise to $50 \%$ by $2020 .^{5}$

Visual impairment (VI) is an important risk factor for falls. Tinetti and Kumar identified eight studies from a systematic review that reported a statistically significant association between VI and falls, with adjusted ORs ranging from 1.7 to $2.3 .^{6}$ Deandra et al identified 15 studies that examined VI as a risk factor for falls in their systematic review, and reported a summary OR of 1.35 (95\% CI 1.18 to 1.54). Additional risk factors include older age, previous falls, chronic diseases and multiple medication use. 157

While previously published studies present strong evidence that VI is a risk factor for falls, detecting VI by objective measures and management with optometric or ophthalmic referrals do not appear to reduce falls. ${ }^{8-10}$ Although these intervention studies suffered from poor compliance and lack of masking, it is possible that visual acuity (VA) measures alone may detect VI but not people at risk of falls due to visual problems. Several studies have shown that selfreported vision (SRV) is related to a variety of objective visual function measures and not solely VA. ${ }^{11}$

In the present study, we investigated the relationship between VA and SRV, and their association with falls in a large older community dwelling population.

\section{METHODS}

The European Prospective Investigation into Cancer (EPIC) and Nutrition study is a 10-country collaborative cohort study investigating lifestyle and nutritional risk factors for cancer. Detailed descriptions of the EPIC study methods and recruitment have been reported previously. ${ }^{12-14}$ The baseline study cohort had lower smoking rates compared with the general Norfolk population, ${ }^{12}$ but were otherwise comparable with regards to anthropometry measures and blood measure. There were also higher proportions of working aged women compared with working aged men, and this age structure is evident among participants attending the follow-up examinations. The present study, the EPIC-Norfolk Eye Study, was based on the third round of clinical examinations, and included a full ophthalmic examination together with a selfadministered health and lifestyle questionnaire, performed between 2004 and 2011. The study was approved by the Norfolk Local Research Ethics Committee and adhered to the Declaration of Helsinki. All participants gave written informed consent.

In the health questionnaire, the participants answered questions relating to physical activity, perception of their visual function and history of falls. SRV was recorded using the question "How good is your eyesight for seeing things at a distance, like recognising a friend from across the street (wearing lenses or glasses if you usually wear them)?" Poor SRV in this study was defined as those reporting fair or poor distance vision; the lowest levels were combined due to low numbers reporting 'poor' vision. History of falls was recorded using the question "How many times have you fallen to the ground in the past year?" The participants were instructed to include falls where any part of the body above the ankle hit the floor or ground and falls which occurred on stairs. Recurrent falls was 
defined as two or more falls. People reporting difficulty with walking a quarter of a mile were asked to select reasons for their difficulties, we categorised people with fear of falling or balance problems in those selecting the answers 'fear of falling' and 'unsteady on feet or balance problems', respectively.

The measurement of habitual physical activity and VA in the EPIC-Norfolk study has been previously described. ${ }^{13}{ }^{15}$ Monocular VA was measured using a logMAR chart (Precision Vision, LaSalle, Illinois, USA) with the aid of the participant's usual distance correction at $4 \mathrm{~m}$. The test was terminated when the participant was able to read $\leq$ three letters on a line and repeated using pinhole-correction if unable to read three letters on the 0.3 line. The physical activity scale used has been validated against heart rate monitoring with individual calibration in independent studies. ${ }^{15}$

A health examination was carried out by trained nurses, following standard operating protocols. Systolic and diastolic blood pressures were recorded as the mean of two measurements taken from the right arm with the participant seated for 5 min, using an Accutorr Plus blood pressure monitor (Mindray, Huntingdon, UK). Height and weight were measured with participants dressed in light clothing and shoes removed. A stadiometer was used to measure height to the nearest $0.1 \mathrm{~m}$, and the Tanita body composition analyser model TBF $300 \mathrm{~s}$ (Chasmors, London) was used to measure weight to the nearest $100 \mathrm{~g}$. Grip strength in each hand was measured using a handheld dynamometer (Smedley's Dynamometer, Scandidact, Kvistgaard, Denmark), with the maximum grip strength from either hand taken as the value for the individual.

The nurse also checked for current medications and the participants were also asked to bring a recent complete prescription of their regular medications with them where relevant. Multiple medications was defined as $\geq$ five recorded medicines. ${ }^{16}$

The EPIC-Norfolk database is linked to national hospital discharge data for Norfolk residents (Hospital Episodes Statistics). Prevalent ischaemic heart disease (IHD) and stroke in this study was ascertained through self-rated disease at baseline (between 1993 and 1997), subsequent health examinations and any recorded episodes of IHD or cardiovascular accident from hospital episodes statistics data accumulated from baseline until 2009.

The data were initially explored through descriptive analysis of variables using $t$ tests for quantitative and $\chi^{2}$ tests for categorical variables to compare different groups. Univariable associations between VA and falls with potential covariates were explored using linear regression, tabulation and $\chi^{2}$ test. A stepwise logistic regression model was used to examine the effect of perceived visual problems and measured VI on risk of falls (history of one or more). Indicator variables were used with all categorical variables in the multivariable analysis. All statistical analyses were conducted using STATA V.10 (Statacorp, College Station, Texas, USA).

\section{RESULTS}

In total, 8623 men and women aged $48-92$ years participated in the EPIC-Norfolk Eye Study, of whom 8405 completed VA tests and the self-administered health questionnaire. A further 88 of this group did not complete the questions on falls leaving 8317 $(96.5 \%)$ participants with complete data for the main variables of interest.

The mean age of participants was 68.6 years, with 3763 $(44.8 \%)$ men and $4642(55.2 \%)$ women. Table 1 shows the

Table 1 Descriptive analysis of 8317 participants with visual function assessment

\begin{tabular}{|c|c|c|c|c|c|}
\hline & \multicolumn{2}{|l|}{ Men } & \multicolumn{2}{|c|}{ Women } & \multirow[b]{2}{*}{${ }^{*} p$ Value } \\
\hline & Mean & (SD) & Mean & (SD) & \\
\hline Mean age & 69.4 & $(8.1)$ & 68.0 & $(8.0)$ & $<0.01$ \\
\hline Mean diastolic blood pressure & 79.6 & $(9.6)$ & 77.1 & $(8.9)$ & $<0.01$ \\
\hline Mean BMI & 27.1 & (3.6) & 26.6 & $(4.8)$ & $<0.01$ \\
\hline \multirow[t]{2}{*}{ Mean maximum grip strength } & 39.1 & (8.3) & 24.4 & $(5.5)$ & $<0.01$ \\
\hline & $\mathrm{n}$ & $(\%)$ & $\mathrm{n}$ & $(\%)$ & \\
\hline Education & & & & & $<0.01$ \\
\hline Less than 0 level & 823 & $(22.1)$ & 1340 & $(29.2)$ & \\
\hline 0 Level & 368 & $(9.9)$ & 623 & (13.6) & \\
\hline A Level & 1780 & $(47.7)$ & 1892 & $(41.3)$ & \\
\hline Degree & 782 & $(20.4)$ & 762 & (15.9) & \\
\hline Physical activity & & & & & $<0.01$ \\
\hline Inactive & 1390 & $(37.2)$ & 1690 & $(36.9)$ & \\
\hline Moderately inactive & 940 & $(25.2)$ & 1486 & (32.4) & \\
\hline Moderately active & 702 & (18.8) & 779 & (17.0) & \\
\hline Active & 702 & (18.8) & 628 & (13.7) & \\
\hline Smoking & & & & & $<0.01$ \\
\hline Current & 156 & $(4.2)$ & 212 & $(4.6)$ & \\
\hline Former & 1905 & $(51.0)$ & 1365 & (29.8) & \\
\hline Never & 1673 & $(44.8)$ & 3006 & (65.6) & \\
\hline IHD & 558 & $(15.0)$ & 262 & $(5.7)$ & $<0.01$ \\
\hline CVA & 93 & $(2.5)$ & 73 & $(1.6)$ & $<0.01$ \\
\hline$\geq 5$ medications & 911 & $(24.4)$ & 1012 & (22.1) & $<0.01$ \\
\hline $\mathrm{N}$ & 3734 & (44.9) & 4583 & (55.1) & \\
\hline
\end{tabular}


Table 2 Snellen visual acuity and perception of eyesight in 8317 people

\begin{tabular}{|c|c|c|c|c|c|c|c|c|c|c|c|}
\hline \multirow{3}{*}{$\begin{array}{l}\text { Presenting visual acuity in better eye } \\
<6 / 9.5\end{array}$} & \multicolumn{10}{|c|}{ Self-reported vision } & \multirow{3}{*}{$\frac{\text { Total }}{7793}$} \\
\hline & \multicolumn{2}{|c|}{ Excellent } & \multicolumn{2}{|c|}{ Very good } & \multicolumn{2}{|l|}{ Good } & \multicolumn{2}{|l|}{ Fair } & \multicolumn{2}{|c|}{ Poor } & \\
\hline & 2304 & (95.7) & 3262 & $(94.7)$ & 1793 & $(90.0)$ & 342 & $(81.2)$ & 44 & (51.8) & \\
\hline $6 / 9.5-6 / 12$ & 66 & $(2.7)$ & 114 & (3.3) & 122 & (602) & 36 & (8.6) & 9 & $(10.6)$ & 351 \\
\hline $6 / 12-6 / 18$ & 35 & $(1.5)$ & 63 & $(1.8)$ & 61 & (3.1) & 26 & $(6.2)$ & 14 & $(16.5)$ & 203 \\
\hline $6 / 18-6 / 60$ & 2 & $(0.1)$ & 6 & $(0.2)$ & 12 & $(0.6)$ & 16 & (3.8) & 9 & (10.6) & 46 \\
\hline$>6 / 60$ & 0 & (0) & 0 & (0) & 1 & $(0.1)$ & 1 & $(0.2)$ & 9 & (10.6) & 12 \\
\hline Total & 2407 & & 3445 & & 1959 & & 421 & & 85 & & 8317 \\
\hline
\end{tabular}

All presented as $n,(\%)$.

descriptive characteristics of the men and women included in this study. Overall, men were older, with higher levels of education, higher diastolic blood pressure, body mass index and grip strength. Women were more likely to be less active, but also less likely to smoke or to have had a history of IHD and stroke. The relationship between SRV and VA is shown in table 2. Using the WHO classification, there were 46 participants $(0.6 \%)$ with low vision (VA 6/18-6/60), and $12(0.1 \%)$ who had severe VI (VA $6 / 60$ or worse). Of these 58 participants with low VA, nearly two-thirds rated their vision as fair or poor $(35 / 58=60.3 \%)$, yet over a third considered their vision as good, very good or excellent $(21 / 58=36.2 \%)$. Conversely, approximately 1 in 20 people with VA better than $6 / 12$ rated their vision as fair or poor (438/ $8144=5.3 \%)$.

Table 3 shows the relationship between risk factors and SRV and VA. Similar associations were observed with all examined risk factors except with sex, where women were more likely to report poor SRV, though there was no association with poorer VA. There was also an indication there were higher proportions of people who were inactive and current smokers who had lower VA compared with proportions reporting poor SRV.

Overall, $26.7 \%$ of all participants reported a fall in the previous 12 months. Table 4 shows that participants who were older, female, inactive, diagnosed with chronic disease, prescribed $\geq$ five medications and with weaker grip strength were more likely to report falls. People with poorer SRV or VA were more likely to report one or more falls. The odds of reporting one or more falls increased with lower levels of VA, with $50 \%$ increased odds at $\mathrm{VA}<6 / 12(\mathrm{OR}=1.52,95 \%$ CI 1.17 to 1.97$)$, over $70 \%$ increased odds at VA $<6 / 18(\mathrm{OR}=1.78,95 \% \mathrm{CI} 1.04$ to 3.06$)$ to over twofold increase in risk with $\mathrm{VA}<6 / 60$

Table 3 Associations between risk factors and vision

\begin{tabular}{|c|c|c|c|c|c|c|c|c|c|c|}
\hline \multirow[b]{3}{*}{ Age } & \multicolumn{5}{|c|}{ Self-reported vision } & \multicolumn{4}{|c|}{ Visual acuity } & \multirow{3}{*}{$\frac{\text { p Value* }}{<0.01}$} \\
\hline & \multicolumn{2}{|c|}{ Excellent-Good } & \multicolumn{2}{|c|}{ Fair/Poor } & \multirow{2}{*}{$\begin{array}{l}\text { p Value* } \\
<0.01\end{array}$} & \multicolumn{2}{|l|}{$\geq 6 / 12$} & \multicolumn{2}{|c|}{ Less than $6 / 12$} & \\
\hline & 68.5 & $(8.0)$ & 70.3 & $(9.0)$ & & 68.4 & $(8.0)$ & 74.5 & $(8.4)$ & \\
\hline Mean diastolic blood pressure & 78.3 & $(9.3)$ & 77.1 & $(9.8)$ & $<0.01$ & 78.3 & $(9.3)$ & 76.5 & $(10.0)$ & $<0.01$ \\
\hline BMI & 26.8 & (4.3) & 26.9 & (4.7) & 0.7 & 26.8 & $(4.3)$ & 26.6 & (3.9) & 0.3 \\
\hline Grip strength & 31.2 & $(10.0)$ & 27.9 & $(9.8)$ & $<0.01$ & 31.1 & $(10.0)$ & 27.1 & $(9.6)$ & $<0.01$ \\
\hline Sex & & & & & $<0.01$ & & & & & 0.3 \\
\hline Male & 3548 & $(45.4)$ & 186 & $(36.8)$ & & 3628 & $(45.0)$ & 106 & $(41.6)$ & \\
\hline Female & 4263 & $(54.6)$ & 320 & $(63.2)$ & & 4434 & $(55.0)$ & 149 & $(58.4)$ & \\
\hline Education & & & & & $<0.01$ & & & & & $<0.01$ \\
\hline Less than 0 level & 1993 & $(25.5)$ & 170 & $(33.7)$ & & 2071 & $(25.7)$ & 92 & $(36.2)$ & \\
\hline 0 Level & 937 & $(12.0)$ & 54 & $(10.7)$ & & 963 & $(12.0)$ & 28 & $(11.0)$ & \\
\hline A Level & 3469 & $(44.4)$ & 203 & $(40.2)$ & & 3573 & (44.3) & 99 & $(39.0)$ & \\
\hline Degree & 1411 & $(18.1)$ & 78 & $(15.5)$ & & 1454 & (18.0) & 35 & $(13.8)$ & \\
\hline Physical activity & & & & & $<0.01$ & & & & & $<0.01$ \\
\hline Inactive & 2851 & $(36.5)$ & 229 & $(45.3)$ & & 2952 & (36.6) & 128 & $(50.2)$ & \\
\hline Moderately inactive & 2286 & $(29.3)$ & 140 & $(27.7)$ & & 2363 & (29.3) & 63 & $(24.7)$ & \\
\hline Moderately active & 1409 & $(18.0)$ & 72 & $(14.2)$ & & 1445 & (17.9) & 36 & $(14.1)$ & \\
\hline Active & 1265 & $(16.2)$ & 65 & $(12.9)$ & & 1302 & $(16.2)$ & 28 & $(11.0)$ & \\
\hline IHD & 696 & (8.9) & 69 & (13.6) & $<0.01$ & 726 & $(9.0)$ & 39 & $(15.3)$ & $<0.01$ \\
\hline CVA & 151 & $(1.9)$ & 15 & (3.0) & 0.1 & 159 & $(2.0)$ & 7 & $(2.8)$ & 0.4 \\
\hline$\geq 5$ medications & 1760 & $(22.5)$ & 163 & $(32.2)$ & $<0.01$ & 1845 & $(22.9)$ & 78 & $(30.6)$ & $<0.01$ \\
\hline Fear of falling & 247 & (3.2) & 45 & $(8.9)$ & $<0.01$ & 271 & $(3.4)$ & 21 & $(8.2)$ & $<0.01$ \\
\hline Problems with balance & 467 & $(6.0)$ & 76 & $(15.0)$ & $<0.01$ & 512 & $(6.4)$ & 31 & $(12.2)$ & $<0.01$ \\
\hline Total & 7811 & & 506 & & & 8062 & & 255 & & \\
\hline
\end{tabular}

Categorical variables presented as $\mathrm{n}(\%)$ and quantitative variables as mean (SD).

* $p$ Value from two sample $t$ test for continuous variables and $\chi^{2}$ test for categorical variables.

BMI, body mass index; CVA, cardiovascular accident; IHD, ischaemic heart disease. 
Table 4 Association between risk factors and falls

\begin{tabular}{|c|c|c|c|c|c|}
\hline & \multicolumn{4}{|l|}{ Falls } & \multirow[b]{2}{*}{ p Value* } \\
\hline & None & & One or & & \\
\hline Age & 68.2 & $(7.9)$ & 69.7 & $(8.5)$ & $<0.01$ \\
\hline Mean diastolic blood pressure & 78.4 & $(9.2)$ & 77.8 & $(9.7)$ & $<0.01$ \\
\hline BMI & 26.7 & $(4.2)$ & 27.2 & $(4.6)$ & $<0.01$ \\
\hline Grip strength & 31.8 & $(10.1)$ & 28.9 & $(9.7)$ & $<0.01$ \\
\hline Sex & & & & & $<0.01$ \\
\hline Male & 2886 & $(47.3)$ & 848 & $(38.2)$ & \\
\hline Female & 3211 & $(52.7)$ & 1372 & $(61.8)$ & \\
\hline Education & & & & & 0.03 \\
\hline Less than 0 level & 1602 & $(26.3)$ & 561 & $(25.3)$ & \\
\hline 0 Level & 752 & $(12.3)$ & 239 & $(10.8)$ & \\
\hline A Level & 2688 & $(44.1)$ & 984 & $(44.3)$ & \\
\hline Degree & 1054 & $(17.3)$ & 435 & $(19.6)$ & \\
\hline Physical activity & & & & & $<0.01$ \\
\hline Inactive & 2163 & (35.5) & 971 & $(41.3)$ & \\
\hline Moderately inactive & 1809 & $(29.7)$ & 617 & $(27.8)$ & \\
\hline Moderately active & 1092 & (17.9) & 389 & $(17.5)$ & \\
\hline Active & 1033 & $(16.9)$ & 297 & (13.4) & \\
\hline IHD & 564 & $(9.3)$ & 256 & (11.6) & $<0.01$ \\
\hline CVA & 102 & $(1.7)$ & 64 & $(2.9)$ & $<0.01$ \\
\hline$\geq 5$ medications & 1286 & $(21.1)$ & 637 & $(28.7)$ & $<0.01$ \\
\hline Fear of falling & 90 & $(1.5)$ & 202 & $(9.1)$ & $<0.01$ \\
\hline Balance & 222 & (3.6) & 321 & $(14.5)$ & $<0.01$ \\
\hline PVA in better eye & & & & & $<0.01$ \\
\hline Better than $6 / 12$ & 5932 & $(97.3)$ & 2130 & $(96.0)$ & \\
\hline $6 / 12-6 / 18$ & 131 & $(2.2)$ & 68 & (3.1) & \\
\hline $6 / 18$ or worse & 34 & $(0.6)$ & 22 & $(1.0)$ & \\
\hline BCVA in better eye & & & & & $<0.01$ \\
\hline Better than $6 / 12$ & 6028 & (98.9) & 2174 & $(98.0)$ & \\
\hline $6 / 12-6 / 18$ & 54 & $(0.9)$ & 36 & $(1.6)$ & \\
\hline $6 / 18$ or worse & 15 & $(0.3)$ & 10 & $(0.5)$ & \\
\hline Perceived visual function & & & & & $<0.01$ \\
\hline Good-Excellent & 5768 & $(94.6)$ & 2043 & $(92.0)$ & \\
\hline Fair/Poor & 329 & $(5.4)$ & 177 & $(8.0)$ & \\
\hline Total & 6097 & & 2220 & & \\
\hline
\end{tabular}

$(\mathrm{OR}=2.29$, 95\% CI 0.70 to 7.51$)$. People reporting poor SRV were also at greater odds of falls with a similar estimate of risk to $\mathrm{VA}<6 / 12(\mathrm{OR}=1.52,95 \% \mathrm{CI} 1.26$ to 1.84$)$.

Multivariable analysis examining the association between VA as a continuous variable and falls adjusting for age, sex, physical activity, history of heart disease and stroke, maximum grip strength, body mass index and $\geq$ five medications showed that 1 unit increase in logMAR VA (equivalent to a change in Snellen VA from 6/6 to 6/60) was associated with a $31 \%$ increase in chance/odds of a fall $(\mathrm{OR}=1.31,95 \%$ CI 1.04 to 1.66, $\mathrm{p}=0.03)$. Furthermore, poor SRV was also associated with a $32 \%$ increased odds of a fall after adjusting for the same covariates $(\mathrm{OR}=1.32,95 \% \mathrm{CI} 1.09$ to $1.61, \mathrm{p}<0.01)$. Combining SRV and VA in the same model to determine the relationship between these two interlinked factors showed that the association between poor SRV and falls was independent of measured VA $(\mathrm{OR}=1.28,95 \% \mathrm{CI} 1.05$ to $1.57, \mathrm{p}=0.01)$. Conversely, the association between VA and falls was no longer statistically significant after accounting for SRV $(\mathrm{OR}=1.24$, 95\% CI 0.98 to $1.58, \mathrm{p}=0.07$ ) (table 5).
Multivariable analysis using dichotomised VA as a risk factor showed that people with VA 6/9.5 or worse were at increased risk of falls $(\mathrm{OR}=1.24,94 \% \mathrm{CI} 1.03$ to $1.50, \mathrm{p}=0.02)$. We used Snellen 6/9.5 acuity as a threshold in line with previous studies which examined the relationship between VA and falls. ${ }^{17}$ Examining VA as a binary variable with threshold criteria at poorer levels of vision showed higher risks of falls, but were not statistically significant with the small numbers and low power. There was no statistical evidence of an interaction between SRV and VA.

\section{DISCUSSION}

In this large population based study of 8317 older people living in the community, we found that VA and SRV were strongly associated with falls. Over a quarter of study participants reported having fallen in the past year. Of those aged 65 years and over, $28 \%$ had fallen in the past year, which is a similar rate to that reported in other retrospective community studies which have reported around 30\% of older people experiencing one or more falls each year. ${ }^{135}$ The overall level of VI was low among 
Table 5 Multivariable adjusted relative risk of one or more reported falls

\begin{tabular}{|c|c|c|c|}
\hline & \multicolumn{3}{|l|}{ Falls } \\
\hline & $\mathrm{OR}$ & $95 \% \mathrm{Cl}$ & $\mathrm{p}$ Value \\
\hline $\begin{array}{l}\text { Model 1: measured visual acuity VA=6/9.5 or } \\
\text { worse and covariates }\end{array}$ & 1.24 & (1.03 to 1.49$)$ & 0.02 \\
\hline $\begin{array}{l}\text { Model 2: subjective visual function and } \\
\text { covariates }\end{array}$ & 1.32 & (1.09 to 1.61$)$ & $<0.01$ \\
\hline \multicolumn{4}{|l|}{$\begin{array}{l}\text { Model 3: measured and subjective visual } \\
\text { function with covariates }\end{array}$} \\
\hline Subjective visual function: Fair/Poor & 1.29 & (1.05 to 1.57$)$ & 0.01 \\
\hline PVA in better eye: $6 / 9.5$ or worse & 1.20 & (0.99 to 1.44$)$ & 0.06 \\
\hline
\end{tabular}

the present study participants, with only $0.7 \%$ (95\% CI $0.5 \%$ to $0.9 \%$ ) categorised as visually impaired by WHO standards (VA 6/18 or worse). The relationship between SRV and falls was statistically significant even after adjusting for VA, suggesting that SRV measures additional aspects of vision-related falls risk.

Several studies have shown that visual function is a strong risk factor for falls. The Beaver $\operatorname{Dam}^{17}$ and Blue Mountains Eye ${ }^{18}$ studies showed that people with VA levels of 6/7.5 or worse and 6/9 or worse, respectively, had a twofold increase in risk of falls. These previously reported risks associated with relatively mild impairment of VA support the findings from the present study and also suggest that the WHO cut-off of 6/18 for VI may not identify a significant proportion of people at risk of falls. A recent meta-analysis summarised 15 heterogeneous studies and found that overall, VI increased risk of all falls with univariable $\mathrm{OR}=1.4$ (95\% CI 1.2 to 1.5$),{ }^{19}$ which is similar to the present study (unadjusted $\mathrm{OR}=1.5,95 \% \mathrm{CI} 1.2$ to 2.0 at VA 6/12 or worse).

There was a strong positive association between VA and SRV, a finding consistent with previous clinical and epidemiological studies. $^{20} 21$ A study of 2467 individuals aged 65 years and over showed that better SRV was associated with higher levels of VA, contrast sensitivity, stereoacuity and visual fields; this suggested that SRV was indicative of other aspects of visual function other than VA. ${ }^{21}$ Despite the strong statistical correlation between SRV and VA, over 50\% of those reporting poor SRV had VA $<6 / 9.5$, supporting the notion that other factors or aspects of vision besides acuity are important to the visual experience. Discrepancies between SRV and VA were also reported from the Salisbury Eye Evaluation study, where the authors found that black patients and people with lower levels of education were more likely to report discordant responses between VA and SRV. $^{22}$ Our population was predominantly white, and we adjusted for education. However, residual confounding and unmeasured non-physiological factors may still have played a role in the observed relationship between SRV and falls and would merit further investigation. We also found evidence of an independent association between SRV with falls after accounting for other risk factors, including VA; this supports the view that other aspects of vision besides VA are important in assessing falls risk. Lord et $a l^{23}$ also showed that other measures of visual function such as contrast sensitivity, visual field and depth perception increased the risk of falls.

It is also possible that SRV measures psychological aspects of falls risk that may not relate to vision. Fear of falling and balance were associated with SRV, VA and falls, but these risk factors are associated with interlinked yet distinct domains of risk ${ }^{24}$ and it was considered inappropriate to adjust for these in our final model since we were investigating visual risk factors. Furthermore, fear of falling and balance are also potential mediators of the effect of vision on falls, and it would be inappropriate to adjust for these in a regression model. Steinman $e a^{25}$ examined participant responses from the Health and Retirement Study and found that SRV was no longer associated with falls after adjusting for upper and lower limb functioning. It is likely that self-reported mobility and SRV are affected by similar non-physiological and psychological domains that influence perception of health status. Adjusting for one would attenuate the effect of the other due to mutual effects but it would be difficult to fully adjust for each factor without objective measures of each risk domain. Nevertheless, our findings suggested that SRV could be used as a simple proxy measure for other aspects of visual function to detect people requiring vision-related falls interventions. There is clear evidence that VI is an important causal factor in the aetiology of falls. However, three well-conducted randomised controlled trials have failed to show a reduction in falls using an intervention that only addressed vision-specific factors; ${ }^{8-10}$ these findings suggested that addressing poor VA alone does not appear effective in preventing falls. In some trials, an increase in falls was detected after provision of new glasses, possibly due to poor adaptation to a new prescription in older people. ${ }^{8} 10$ Taking SRV into account to stratify risk may mitigate the unexpected countereffect following provision of new glasses.

There are limitations of the present study: the study prevalence of VI was low, as were the levels of chronic diseases. The study related to the third follow-up of a large population cohort and therefore the survivors who participate would have been relatively healthy compared with the general population. Also, people who have visual problems or were unwell were less likely to attend the clinic for the ophthalmic examination. However, since nonattenders were more likely to have fallen or suffered from VI, the association detected was likely to have been underestimated. We chose to collapse two categories of SRV together ('fair' and 'poor') due to small numbers in the 'poor' category. There is likely to be heterogeneity in the resulting group though the directions of the associations are likely to be similar. There was also potential measurement error in SRV and falls, in that frequency of falls in the study was self-reported and participants were asked to recall falls over the previous 12 months. There may have been limited accuracy in recall over 12 months, resulting in under-reporting of falls. ${ }^{26}$ However, random measurement error generally attenuates any association detected and again would have resulted in an underestimation of the number of falls. Recall bias may also have been present, and people whose SRV was poor may have been more likely to have recalled falls, whereas people who reported good visual function may have blamed falls on external factors. ${ }^{3}$ Nevertheless, SRV and VA were strongly correlated and there was also a strong association between VA and falls; this would have reduced the potential effect of this bias.

Falls are an important public health problem for community dwelling older people and falls prevention programmes are effective when targeted appropriately. Based on the findings of the present study, SRV serves as a suitable indicator of falls risk.

Acknowledgements The authors would like to thank Pak S Lee for the training of research clinic nursing staff and equipment maintenance.

Contributors The authors all fulfil the ICJME criteria for authorship.

Funding EPIC-Norfolk infrastructure and core functions are supported by grants from the Medical Research Council (G1000143) and Cancer Research UK (C864) A14136). The clinic for the third health examination was funded by Research into Ageing (262). 
Competing interests APK is a Wellcome Trust Clinical Research Fellow. PJF has received additional support from the Richard Desmond Charitable Trust (via Fight for Sight) and the Department for Health through the award made by the National Institute for Health Research to Moorfields Eye Hospital and the UCL Institute of Ophthalmology for a specialist Biomedical Research Centre for Ophthalmology.

Ethics approval Norfolk Local Research Ethics Committee.

Provenance and peer review Not commissioned; externally peer reviewed.

Data sharing statement All data requests and potential collaborations are reviewed by the EPIC-Norfolk management committee.

Open Access This is an Open Access article distributed in accordance with the Creative Commons Attribution Non Commercial (CC BY-NC 3.0) license, which permits others to distribute, remix, adapt, build upon this work non-commercially, and license their derivative works on different terms, provided the original work is properly cited and the use is non-commercial. See: http://creativecommons.org/ licenses/by-nc/3.0/

\section{REFERENCES}

1 Campbell AJ, Borrie MJ, Spears GF. Risk factors for falls in a community-based prospective study of people 70 years and older. J Gerontol 1989;44:M112-17.

2 Tinetti ME, Speechley M, Ginter SF. Risk factors for falls among elderly persons living in the community. N Engl J Med 1988;319:1701-7.

3 Lord S, Sherrington C, Menz H. Falls in older people: risk factors and strategies for prevention. Cambridge University Press, 2001.

4 NICE Guideline CG21. Clinical practice guideline for the assessment and prevention of falls in older people. 2004.

5 Gillespie LD, Robertson MC, Gillespie WJ, et al. Interventions for preventing falls in older people living in the community. Cochrane Database Syst Rev 2012;9:CD007146.

6 Tinetti ME, Kumar C. The patient who falls: "It's always a trade-off". JAMA 2010;303:258-66.

7 Tinetti ME, Inouye SK, Gill TM, et al. Shared risk factors for falls, incontinence, and functional dependence. Unifying the approach to geriatric syndromes. JAMA 1995;273:1348-53.

8 Cumming RG, Ivers $\mathrm{R}$, Clemson $\mathrm{L}$, et al. Improving vision to prevent falls in frail older people: a randomized trial. J Am Geriatr Soc 2007;55:175-81.

9 Day L, Fildes B, Gordon I, et al. Randomised factorial trial of falls prevention among older people living in their own homes. BMJ 2002;325:128.

10 Haran MJ, Cameron ID, Ivers RQ, et al. Effect on falls of providing single lens distance vision glasses to multifocal glasses wearers: VISIBLE randomised controlled trial. BMJ 2010;340:c2265.

11 Rubin GS, Bandeen-Roche K, Huang GH, et al. The association of multiple visual impairments with self-reported visual disability: SEE project. Invest Ophthalmol Vis Sci 2001:42:64-72.
12 Day $N$, Oakes $\mathrm{S}$, Luben $\mathrm{R}$, et al. EPIC-Norfolk: study design and characteristics of the cohort. European Prospective Investigation of Cancer. Br J Cancer 1999;80 (Suppl 1):95-103.

13 Khawaja AP, Chan MP, Hayat S, et al. The EPIC-Norfolk Eye Study: rationale, methods and a cross-sectional analysis of visual impairment in a population-based cohort. BMJ Open 2013;3:e002684.

14 Hayat SA, Luben R, Keevil VL, et al. Cohort Profile: A prospective cohort study of objective physical and cognitive capability and visual health in an ageing population of men and women in Norfolk (EPIC-Norfolk 3). Int J Epidemiol Published Online First: 14 Jun 2013. doi:10.1093/ije/dyt086

15 Khaw KT, Jakes R, Bingham S, et al. Work and leisure time physical activity assessed using a simple, pragmatic, validated questionnaire and incident cardiovascular disease and all-cause mortality in men and women: The European Prospective Investigation into Cancer in Norfolk prospective population study. Int J Epidemiol 2006;35:1034-43.

16 Gnjidic D, Hilmer SN, Blyth FM, et al. Polypharmacy cutoff and outcomes: five or more medicines were used to identify community-dwelling older men at risk of different adverse outcomes. J Clin Epidemiol 2012;65:989-95.

17 Klein BE, Klein R, Lee KE, et al. Performance-based and self-assessed measures of visual function as related to history of falls, hip fractures, and measured gait time. The Beaver Dam Eye Study. Ophthalmology 1998;105:160-4.

18 Ivers RQ, Cumming RG, Mitchell $P$, et al. Visual impairment and falls in older adults: the Blue Mountains Eye Study. J Am Geriatr Soc 1998;46:58-64.

19 Deandrea S, Lucenteforte E, Bravi F, et al. Risk factors for falls in community-dwelling older people: a systematic review and meta-analysis. Epidemiology 2010;21:658-68.

20 Adamsons IA, Vitale S, Stark WJ, et al. The association of postoperative subjective visual function with acuity, glare, and contrast sensitivity in patients with early cataract. Arch Ophthalmol 1996;114:529-36.

21 El-Gasim M, Munoz B, West SK, et al. Associations Between Self-Rated Vision Score, Vision Tests, and Self-Reported Visual Function in the Salisbury Eye Evaluation Study. Invest Ophthalmol Vis Sci 2013;54:6439-45.

22 El-Gasim M, Munoz B, West SK, et al. Discrepancies in the concordance of self-reported vision status and visual acuity in the Salisbury Eye Evaluation Study. Ophthalmology 2012;119:106-11.

23 Lord SR, Dayhew J. Visual risk factors for falls in older people. J Am Geriatr Soc 2001;49:508-15.

24 Kotecha A, Chopra R, Fahy RT, et al. Dual tasking and balance in those with central and peripheral vision loss. Invest Ophthalmol Vis Sci 2013 54:5408-15.

25 Steinman BA, Pynoos J, Nguyen AQ. Fall risk in older adults: roles of self-rated vision, home modifications, and limb function. J Aging Health 2009; 21:655-76

26 Cummings SR, Nevitt MC, Kidd S. Forgetting falls. The limited accuracy of recall of falls in the elderly. J Am Geriatr Soc 1988:36:613-16. 